\title{
CUERVOS Y BÚHOS: LA METÁFORA COMO ELEMENTO PRAGMÁTICO EN REFRANES DE LA DARIYA Y DEL ESPAÑOL PENINSULAR
}

\author{
Carmen VICENTE MOLINERO*
}

Universidad de Zaragoza

BIBLID [1133-8571] 26 (2019) 19.1-20.

Resumen: En este artículo estudiaremos la metáfora como un elemento especialmente problemático en la ASL. Usaremos principios de la lingüística cognitiva para analizar las características de la metáfora conceptual y de su expresión linguiística. Por otro lado, se hablará también de cómo la lengua y la cultura influyen en la metáfora conceptual. Con tal objetivo, usaremos un corpus de refranes e idiomatismos en dariya y en español. Creemos que este análisis servirá para desarrollar materiales de ELE que se aproximen a este tipo de cuestiones, que son normalmente obviadas en la clase de idiomas.

Palabras clave: Metáfora conceptual, Expresión lingüística metafórica, Dariya, Español, ELE.

\begin{abstract}
Crows and owls: the metaphor as pragmatic element in proverbs of Dariya and Peninsular Spanish». In this paper, we will study the metaphor as a pragmatic problematic element in the ASL. We will use principles of cognitive linguistic to analyze the characteristics of the conceptual metaphor and its linguistic expression. On the other hand, we will also discuss how the conceptual metaphor is influenced both by the language and the culture. For this purpose, we will use a corpus of proverbs and idioms in Dariya and in Spanish. This analysis will then be use to develop ELE's materials that approach this type of questions, but are normally forgotten in the classroom of languages.

Key words: Conceptual Metaphor, Linguistic Metaphor Expression, Dariya, Spanish, ELE.

ملخص: 》الغربان والبوم: الاستعارة كعنصر براغماتي في الامثال بالدارجة والاسبانية في شبه الجزيرة الايييرية). سندرس في هذا هلئ

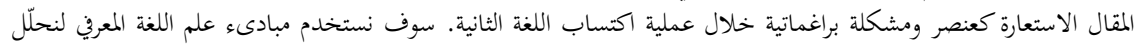

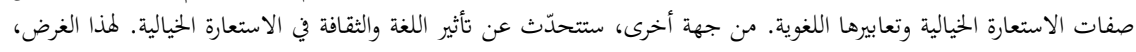

* E-mail: mamenele@hotmail.com. 


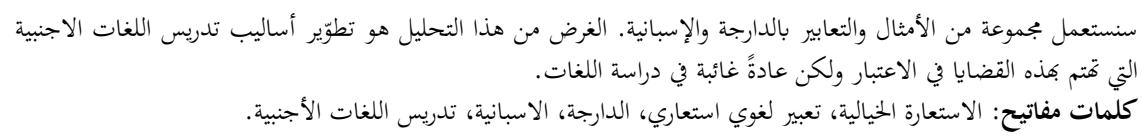

\section{Introducción}

Consideramos que la metáfora se configura como un objeto de análisis sociolingüístico realmente interesante de la L1 (lengua materna) y del proceso de adquisición de segundas lenguas debido a que:

a) en la actualidad, la mayoría de las investigaciones pragmáticas y cognitivas coinciden en definir la metáfora como un fenómeno de la mente humana, al observar que la mayor parte de los enunciados metafóricos que se usan en la vida diaria no persiguen lograr ningún efecto estético y, además, se ven influidos significativamente por el contexto en el que aparecen (Parente 2000);

b) la metáfora constituye un elemento pragmático especialmente problemático en la adquisición de segundas lenguas (en adelante, ASL) y en todo tipo de situaciones comunicativas interculturales por la influencia que tienen en ella la cultura y la lengua del hablante. Los malentendidos que provoca pueden hacer peligrar la comunicación intercultural en mayor medida que otro tipo de incorrecciones (fonéticas, léxicas, sintácticas) porque al interlocutor le cuesta mayor procesamiento mental su reparación pragmática (Merino Jular 2010).

\section{Apuntes pragmáticos sobre la metáfora}

Algunas expresiones lingüísticas pueden ser interpretadas de forma literal en un contexto y metafóricamente en otro. Como explicación a este fenómeno, la pragmática expone que el significado metafórico de un enunciado se manifiesta en la interacción humana (Anaki, Faust \& Kravetz 1998), es decir, en la actuación lingüística.

La pragmática se ha preocupado del estudio de la metáfora por dos razones diferenciadas: i) por su gran presencia en el uso diario de la lengua ${ }^{(1)} y$ ii) por la influencia que tienen en ella el contexto y los conocimientos compartidos entre los interlocutores. Estos dos hechos convierten a la metáfora

(1) La mayoría de las metáforas se usan en el lenguaje común. Se las denomina «metáforas convencionales» o «metáforas en las que vivimos» (Lakoff \& Johnson 1980): por ejemplo, hacer de tripas corazón, en español, o no tener ni un nabo, en árabe. 
en un elemento especialmente interesante para el estudio de la adquisición sociolinguística, tanto en la lengua materna como en la adquisición de segundas lenguas (ASL).

La sociolingüística, como parte de la pragmática, intenta descubrir, por un lado, cómo es posible que no coincida lo que dice el emisor y lo que quiere decir y que este hecho no impida la comunicación (Curcó 1998). Por otro lado, intenta determinar cuáles son los mecanismos para la comprensión de las metáforas: si el receptor solo pone en funcionamiento la codificación y descodificación lingüística no será capaz de identificar el significado último que un emisor pretende comunicar a través de una metáfora. Lo literal se comprende sin dificultad, pero lo metafórico debe ser inferido. Para ello, el receptor acciona determinadas implicaturas (Grice 1989, Sperber \& Wilson 1986 y Curcó, 2014), que alcanzarán el verdadero significado del enunciado en unas circunstancias comunicativas determinadas. A causa de ello, la Teoría de la Relevancia (Sperber y Wilson, 1986) subraya la importancia que tienen en la comunicación humana las intenciones de los interlocutores, su relación y el contexto en el que tiene lugar una situación comunicativa, ya que el mecanismo de la metáfora se desarrolla implementando un razonamiento pragmático según las variables en las cuales aparece (Nunberg, Sag \& Wasow, 1994).

Es un hecho que las corrientes pragmáticas coinciden en atribuir a la metáfora importantes funciones en las interacciones humanas: por ejemplo, el individuo puede usarlas como herramientas de creación léxica. Su uso posibilita al hablante aumentar el vocabulario de una lengua, como con la relexificación, es decir, otorgar un nuevo nombre a un objeto que ya tenía denominación: maderos en España o hanach $^{(2)}$ («serpientes») en Marruecos, en ambos con el nuevo significado de «policías».

Asimismo, el hablante utiliza la metáfora para poder explicar y comprender conceptos abstractos partiendo de otros conceptos más concretos. De esta forma, el hablante usa metáforas para referirse a i) experiencias amorosas: estar enamorado hasta los huesos, en español o querer hasta el corazón en dariya; ii) estados físicos: llegar agotado, en español, o no llegar

(2) En estos ejemplos, nos hemos limitado a presentar la traducción de las expresiones metafóricas al español, ya que sus transcripciones en árabe, en su gran mayoría, se pueden encontrar en Moscoso (2010). Consideramos que la lectura se hace así mucho más dinámica y no entorpece al fin último de nuestro artículo. 
hasta ver sus ojos en la nuca, en dariya (con la traducción adaptada en español de «llegar cansado»); iii) estados de salud: en español, estar en fase terminal o en árabe marroquí empezar mi vientre a golpear el violín (con la traducción adaptada en español: «tener hambre»); iv) los estados de ánimo: estar de bajón, en español, o llorar hasta quedar ciego en dariya; v) las descripciones físicas: estar hecho un palillo o estar dotado de vientre en dariya (con su traducción adaptada en español de «tener barriga») y vi) las descripciones psicológicas: ser un cara dura, en español o en dariya menos vergüenza y su traducción adaptada en español: «ser un caradura o un sinvergüenza».

En tercer lugar, las metáforas son usadas por el hablante como mecanismos de intensificación y atenuación (Fernández Colomer \& Albelda 2001 y Fernández Colomer 2003). Las palabras con significado figurado aportan una mayor significación y expresividad a la información transmitida y sirven para ser más directos. Así, mientras que el eufemismo se utiliza como procedimiento atenuador de ciertos ámbitos temáticos que pueden considerarse tabú como la muerte o el sexo (en español fallecer, fenecer, expirar por morir, por ejemplo, o agujerear por violar en dariya y salir de cuentas / terminar las cuentas para parir en ambos idiomas (Moscoso, 2010), el disfemismo -más frecuente en el registro coloquial, ya que es un fenómeno habitual cuando la relación entre los interlocutores es de proximidad y de igualdad (Albelda 2005) se usa para intensificar el mensaje. Por ejemplo, se encuentran como sinónimos de morir, los disfemismos estirar la pata en español y colgarse en dariya.

\section{Aportaciones de la Lingüística Cognitiva al estudio de la metáfora conceptual y la metáfora lingüística}

Por su parte, los estudios cognitivos sobre la metáfora se inician al final de los años 70. En estas fechas, Pollio (1977) comienza a interesarse por la metáfora como habilidad creativa de la comunicación de los seres humanos. Desde entonces, las investigaciones cognitivas sobre la metáfora han puesto de manifiesto que el lenguaje verbal es un código guiado en parte por el pensamiento metafórico (Danesi 2014).

La lingüística cognitiva se aparta de la visión chomskiana sobre la metáfora, dejándola de considerar un mecanismo anómalo de la lengua y pasa a interpretarla como parte de la cognición del ser humano (Soriano 2012), es decir, un mecanismo que radica en el sistema conceptual de los hablantes, apoyándose en aspectos elementales y cotidianos (Lakoff \& Johnson 1986) y 
que sirve para estructurar el sistema conceptual de una cultura (Lakoff \& Johnson, 2003). La metáfora es una proyección mental tan importante que influye en la forma en que el ser humano piensa, razona o imagina en su vida cotidiana (Gibbs 2010).

La lingüística cognitiva insiste, además, en no confundir la idea de «metáfora conceptual» con la de su expresión lingüística metafórica o «metáfora lingüística» (Lakoff y Turner 1989). Las expresiones lingüísticas metafóricas concretan la metáfora conceptual únicamente en el plano lingüístico. Están compuestas por palabras o expresiones que funcionan en un contexto determinado. No obstante, la metáfora conceptual y la metáfora lingüística se hallan fuertemente interrelacionadas, ya que el hablante necesita hallar la metáfora conceptual de partida para resolver la incongruencia del enunciado donde aparece una metáfora lingüística.

Como la pragmática, la lingüística cognitiva defiende la existencia de inferencias en el proceso de la comunicación, pero va más allá, ya que considera que dichas inferencias se guían principalmente por proyecciones metafóricas y por los conocimientos previos compartidos entre los interlocutores (Gibbs 1994). Más concretamente, la metáfora es el conjunto de correspondencias conceptuales entre dos dominios de conocimiento, uno específico y otro abstracto (Ruiz de Mendoza \& Del Campo, 2012). Uno de estos dominios, el más concreto o cercano a la experiencia fuente -«dominio fuente»- se utiliza para estructurar un campo conceptual más abstracto, el «dominio meta o destino». Por ejemplo, si utilizamos la metáfora lingüística («lo que el lenguaje expresa», según Lakoff \& Turner 1989) tengo los ánimos por los suelos, partimos de la metáfora conceptual ABAJO ES MALO ${ }^{(3)}$, en la cual ABAJO es el dominio meta y MALO el dominio fuente. El hablante proyecta únicamente la información, la selección de rasgos del dominio fuente, que considera coherente con el dominio meta, ya que si las proyecciones fueran completas, el resultado sería que EL DOMINIO FUENTE es EL DOMINIO META y se perdería el sentido metafórico (Lakoff 1990). El cognitivismo afirma que para las construcciones metafóricas se utilizan solo las «propiedades prototípicas» más importantes para una cultura (Ibarretxe-Antuñano 1999). Así, una metáfora

(3) La lingüística cognitiva aplica la fórmula (siempre en mayúsculas) EL DOMINIO META ES EL DOMINIO FUENTE a la metáfora conceptual. Esta ecuación parece servir para todas las lenguas (Soriano 2012). 
resulta ser al mismo tiempo un fenómeno cognitivo corporeizado, basado en la experiencia de los individuos, y cultural. Este hecho permite explorar qué es lo universal y qué es lo específico de las representaciones metafóricas en distintos idiomas.

Por esta razón, una de las características más relevantes para el estudio de la lengua materna y de la ASL de la metáfora conceptual (y lingüística) es que su motivación no es arbitraria (Bustos 2000), sino que responde a diferentes razones. Según la escuela cognitiva, el origen principal de la producción de metáforas radica en la experiencia del hablante, de su entorno y del cuerpo desde el que percibe la realidad. Efectivamente, el cognitivismo afirma que gran parte de las metáforas están corporeizadas (Lakoff \& Kovecses 1987, Bustos 2000 y Gibbs 2006). Esto explicaría por qué muchas de las metáforas conceptuales son comunes en muchas lenguas, aunque no lo sean sus expresiones metafóricas (Casasanto 2009). Parece que las lenguas comparten conceptos «básicos» metafóricos, basados en experiencias sensoriales o motoras del hablante (Pamiés Beltrán 2002). Existen, por ello, metáforas lingüísticas como se le heló el corazón en español o paró su corazón en árabe con el sentido de sufrir un infarto o ser un burro con el sentido de ser una persona bruta y ruda en España e inculto en Marruecos, que parten de metáforas conceptuales EL CUERPO ES UNA MÁQUINA o LOS HOMBRES SON ANIMALES.

No obstante, el parecido entre ambos dominios puede sustentarse además en la experiencia cultural del sujeto (Sharifian y Palmer 2007): la corporeización, la base experiencial y la percepción del parecido tienen lugar en el marco de una cultura específica (Jakel 1997, Kovecsses 2000 y Sharifian \& Palmer 2007). Las metáforas conceptuales actúan como un código de valores culturales que comparten los individuos de una comunidad cultural y/o lingüística que el hablante de una lengua tiende a repetir (Duffé Montalván 2004). Así, el número de metáforas conceptuales puede ser en teoría infinito, pero la cultura limita estos esquemas a un número determinado.

De forma no menos importante que en la configuración de la metáfora conceptual, la cultura influye también en la expresión de la metáfora lingüística (Santiago, Lupáñez, Pérez \& Funes 2007). La costumbre dirige al individuo a poner en funcionamiento determinados esquemas metafóricos típicamente culturales que reflejan los valores de referencia compartidos por un colectivo (Danesi 2004). De este modo, las metáforas conceptuales, comunes en diferentes lenguas, pueden diferir en su expresión lingüística. 
Por ejemplo, si se atiende a la actitud de las sociedades árabe y española ante la naturaleza que, aunque suele comprender nociones universales, también se halla influida por la cultura del individuo, es posible encontrar:

a) ligeras variaciones en las expresiones lingüísticas de la metáfora conceptual, con el mismo significado, usando en ambos idiomas elementos de la naturaleza (Ziyad Gogazeh 2005):

español: una golondrina no hace verano

árabe: una rosalflor no hace primavera

b) expresiones lingüísticas totalmente diferentes, con el mismo significado, usando en ambos idiomas elementos de la naturaleza:

español: pedir la luna

árabe: pedir la leche al pájaro

Todas estas características de la metáfora permiten clasificarla de diferentes formas. Por un lado, Lakoff y Johnson (1986) las categorizan según su función y presentan tres tipos de metáforas conceptuales: «orientacionales, ontológicas y estructurales». Las metáforas orientacionales y las ontológicas suelen ser comunes entre las diversas lenguas y culturas y no son muy productivas en cuanto a expresiones metafóricas lingüísticas, mientras que las estructurales son más prolíficas y se construyen dentro del sistema cultural en donde se vive. Por esta razón, este tipo de metáforas resultarán especialmente problemáticas en la ASL.

a) Metáforas orientacionales: son un importante ejemplo de la cotidianeidad de la metáfora en las interacciones de los hablantes. La mayoría están relacionadas con la orientación espacial y con la corporeización del sujeto. Ya hemos visto que, en una gran parte de las lenguas, lo óptimo se identifica con arriba y lo pésimo con abajo (Lakoff \& Johnson, 1980). Así, encontramos me levantó el ánimo, mi moral cayó por los suelos en español o estar ahogado en dariya (con la traducción adaptada al español de «estar deprimido»).

b) Metáforas ontológicas: se categoriza un fenómeno abstracto como una sustancia, un contenedor, una persona. Así, la metáfora conceptual LA CABEZA ES UN RECIPIENTE (Lakoff \& Johnson 1980) produce metáforas lingüísticas como explotar la cabeza en dariya y en español. 
c) Metáforas estructurales: una actividad o experiencia se estructura en términos de otra: por ejemplo, UN DISCURSO EN UN TEJIDO (Millán \& Narotzky 2009), con las expresiones metafóricas me has hecho perder el hilo en español y me has hecho olvidar la cabeza del hilo en árabe marroquí (Moscoso, 2010).

Soriano (2012) propone, por su parte, la siguiente categorización:

a) Según la estructura de la metáfora se habla de: i) «proyecciones de una sola correspondencia», en las cuales solo un dato, el de mayor relevancia, es el que se traslada del dominio fuente al dominio destino: en Miguel es un zorro / Mohammed es un zorro se exporta a la persona el rasgo de inteligencia y astucia, atribuida a dicho animal en ambos idiomas y ii) «proyecciones de varias correspondencias» en las que las correspondencias más complejas permiten expandir las inferencias (Ruiz de Mendoza 1996, 2000), creando todo un sistema metafórico (Lakoff \& Johnson, 1998). Si el ser humano percibe su cuerpo como contenedor de sustancias y las emociones como sustancias que pueden ser contenidas surgen metáforas lingüísticas como estar hasta las narices, en español, o salir felicidad por los ojos en árabe marroquí.

b) Según la motivación existen «metáforas correlacionales y metáforas de parecido» (Grady 1997). En las correlacionales la relación entre los dominios surge de la experiencia y de la interacción con el mundo, como EL AFECTO ES CALOR. Las metáforas de parecido, sin embargo, se crean a partir de un cierto parecido, que no tiene por qué ser objetivo y literal, sino que puede ser un significado que el hablante construye por influencia cultural. Estas metáforas son muy abundantes en todas las lenguas y actúan en las zonas temáticas importantes para los individuos de una determinada sociedad. Destacan las que dan lugar a: i) expresiones metafóricas del mundo vegetal (González Pérez 2008), como, por ejemplo, en LAS PERSONAS SON PLANTAS O VEGETALES las metáforas lingüísticas estar hecho un roble, estar sano como una manzana (Vela 2014) en español el árbol nace de una semilla, ser tan iguales como dos dátiles (Ould Mohammed Baba 1996) y ii) expresiones metafóricas del mundo animal: estar como una cabra, empollar, morir como una rata (Vela 2014), en español, o sudar como caballo corredor en árabe (Ould Mohammed Baba 1996).

c) Según la complejidad de la metáfora conceptual, Soriano (2012) habla de «metáforas compuestas», que son indivisibles como tener angustia en el 
corazón de la que se extrae la metáfora conceptual EL CUERPO ES UN CONTENEDOR y LAS EMOCIONES SON SUSTANCIAS en español o tener el corazón negro en árabe marroquí, en la cual LAS PARTES DEL CUERPO SON CUALIDADES Y EL NEGRO ES MALO. Por su parte, existen las metáforas primarias, como LOS HOMBRES SON ANIMALES, con ejemplos como la cabra siempre tira al monte, en español o el perro es león en su propia casa en árabe (Andújar García 2016).

d) Según el grado de convencionalidad de la metáfora, Soriano (2012) clasifica las metáforas lingüísticas en i) «metáforas convencionales», que están arraigadas en el uso cotidiano del idioma. Por ejemplo la expresión echar humo por las orejas, que en español significa pensar mucho o estar enfadado, aparece en la vida diaria de los hablantes, del mismo modo que en árabe marroquí encontramos producir niebla con el significado de «pensar mucho en soledad». Estas metáforas lingüísticas son comprendidas y compartidas por los hablantes de estas lenguas. Y ii) «metáforas creativas o literarias», que exigen, según Lakoff y Turner (1989), un mayor grado de procesamiento o incluso un mayor grado de intimidad entre los interlocutores, en función de unos saberes y creencias compartidos. Por ejemplo, la metáfora lingüística que aparece en Finito se cortó la coleta en las Ventas difícilmente sería comprendida por quien desconozca el funcionamiento de la tauromaquia (Chamizo Domínguez 2005) o Alá creó la Tierra en seis días (con la equivalencia en español de Zamora no se conquistó en una hora) (Andújar García 2016) podría sorprender a un hablante que no tenga conocimientos sobre el islam.

En definitiva, a pesar de que el hablante no nativo pueda entender (o al menos intuir) el significado último de la mayoría de las expresiones metafóricas de una L2 (lengua segunda, lengua meta) porque presentan algunos rasgos comunes con su L1, en ocasiones pueden resultar problemáticas al no compartir los hablantes de una interacción intercultural todos los conocimientos y creencias socioculturales previos necesarios. Por esta razón, creemos que la metáfora, tanto conceptual como lingüística, se revela como un elemento sociolingüístico suficientemente importante para ser tenido en cuenta en el proceso de ASL. 
3. La metáfora como elemento lingüístico de expresión cultural: semejanzas y diferencias entre la dariya y el español peninsular

Nuestro estudio sobre la metáfora en español y en dariya se ha basado en los datos extraídos de un corpus de elaboración propia obtenido a través de la lectura bibliográfica de artículos sobre refranes y proverbios ${ }^{(4)}$ y la consulta a hablantes nativos de árabe marroquí. El objetivo ha sido analizar la forma de producir metáforas conceptuales y sus correspondientes expresiones metafóricas de los hablantes de dariya para compararlas con las metáforas conceptuales y expresiones metafóricas de los hablantes de español peninsular y encontrar posibles semejanzas y diferencias entre ambas lenguas. Consideramos que los resultados son útiles para una posterior práctica docente de profesores de ELE con aprendientes con la dariya como lengua materna.

\subsection{Refranes y proverbios}

A grandes rasgos, el refrán se puede definir como una expresión metafórica que, en su conjunto, posee un significado connotativo, subjetivo y contextual que sus elementos de forma aislada no presentan. Su lectura denotativa es irrelevante: su significado último se ajusta más a la pragmática que a la semántica ya que el hablante al emitirlos emite su apreciación sobre la interacción comunicativa y quiere causar en el receptor un efecto que no se halla en la semántica estricta. De esta forma, el significado del refrán es ante todo extralingüístico y pragmático, porque aparece relacionado con las experiencias de una comunidad determinada y del individuo que lo emite.

Además, los refranes se han considerado tradicionalmente como la expresión de un pensamiento de sabiduría popular que no suele variar significativamente de una lengua a otra (Ruiz de Mendoza 2000). Su función y su contenido también pueden considerarse cuasi-universales, porque en todas las lenguas sirven para expresar las experiencias internas y externas del individuo, categorizar los grupos humanos y distribuir roles entre ellos. Suelen expresar reflexiones similares ante situaciones semejantes en casi todas las culturas, aunque pueden diferir en su forma de expresarlas. Efectivamente, podemos

(4) Todos los ejemplos de refranes y proverbios utilizados provienen de fuentes bibliográficas (Ruiz Moreno 2000, Boughaba 2014, Eldin Shalan 2012, El Madkouri 2010, Ziyad Gogazeh, 2005, Sevilla Muñoz y Crida Álvarez 2013). 
comprobar que en ambos idiomas -español / dariya $a^{(5)}$ - los refranes comparten una serie de características ${ }^{(6)}$ :

a) Se suprimen verbos en su enunciación, es decir, suelen ser frecuentes las construcciones nominales: Perro ladrador, poco mordedor; como el tambor: recia voz, hueco interior.

b) Se usa el presente con valor de atemporalidad: Quien a buen árbol se arrima, buena sombra lo cobija; El fuerte se come al débil.

c) Muchas veces, los refranes son construcciones bimembres: En casa del herrero, cuchillo de palo; Este mundo es un espejo, muéstrate y te mostrará.

d) Cada parte en los refranes bimembres suele tener el mismo número de elementos: Más vale bueno conocido que bueno por conocer; Tienes un pariente, tienes un enemigo.

e) Se altera el orden lógico de la oración: A buen entendedor, pocas palabras bastan; Bien entiende la madre del mudo el lenguaje de su hijo. En dariya el hipérbaton es una construcción incluso más anómala que en español, porque en el árabe clásico casi ni existe. De esta manera su uso en los refranes produce extrañamiento y facilita así la memorización.

f) Suelen aparecer topónimos y antropónimos. En ambos idiomas los antropónimos sirven como símbolos: por ejemplo en español Juan representa al pueblo y a la simpleza y en dariya Hatim a la generosidad (Martínez Kleiser, 1978). Una característica del árabe es que suelen aparecer emparejados: casad a Miskah con Rim, ninguno vale nada. El uso de los topónimos también es habitual en los dos idiomas: salir de Málaga y caer en Malagón; cásate en Granada y muere en Vélez.

g) En dariya destaca la existencia de refranes en forma de interrogación retórica o diálogo, algo menos habitual en español: Si yo soy ama y tú eres ama, ¿Quién limpiará la palangana?; Y tu padre, ¿qué te dejó? Un cabrito que murió. En español encontramos ejemplos del tipo: $Y$ dijo la sartén al cazo: ¡Quítate de ahí, ojinegra! o ¿A dónde vas? A los toros. ¿De dónde vienes? De los toros.

(5) Debemos señalar que los hablantes nativos de dariya suelen formular los refranes en árabe clásico, sin que este cambio de idioma produzca extrañeza en su interlocutor.

(6) En cada uno de los ejemplos, el primer refrán se formula en español y el segundo se corresponde con la traducción del árabe a español. 
h) Ambos idiomas usan la metáfora con una intención pedagógica. Pretenden facilitar la comprensión de una idea ejemplificándola: uno por el otro, la casa sin barrer (simbolizando la casa un asunto o tarea a realizar); no distingue un dátil de la luna (simbolizando un dátil un problema mínimo y la luna uno grave).

A pesar de la existencia de todas estas características comunes entre los refranes de las dos lenguas, la traducción de refranes entre ambos idiomas resulta muchas veces problemática. Esto es debido a que en ocasiones hay que transferir conceptos culturales de una lengua a otra, de los que los refranes están impregnados. La cultura incluye el conocimiento, las creencias, el arte, la moral, la religión, las costumbres... y ninguno de estos factores tiene menos importancia que otros para la configuración del uso del lenguaje del sujeto. Por eso, ante la interpretación de los refranes por parte de individuos de otras lenguas y/o culturas pueden ocurrir varias cosas:

a) que la comprensión no sea problemática porque las expresiones, los significados y las funciones se correspondan (Ziyad Gogazeh 2005): Esto es como huir del fuego para caer en las brasas, Esto es como el que recurre al fuego para protegerse del ardor o porque la función se corresponda variando levemente la expresión: a buen entendedor pocas palabras bastan, un inteligente con un gesto entiende.

b) puede haber refranes en los cuales los significados figurados se correspondan, pero en los que las expresiones metafóricas sean totalmente diferentes: cría cuervos y te sacarán los ojos, acompaña al búho y te llevará al desastre.

c) Puede ocurrir que determinadas características culturales sean tan definitorias que produzcan refranes totalmente diferentes y aparezcan formas particulares de las expresiones metafóricas. De esta forma, la comprensión completa no se puede lograr sin el conocimiento de ambas culturas. Además, estas características pueden producir proverbios y refranes que existan en una lengua, pero que no tengan ningún equivalente en la otra, ya que la conceptualización de las experiencias de los individuos se halla muy alejada.

Por ejemplo, como ya se ha señalado, la actitud (cultural) de una sociedad ante el clima puede ser diferente para cada lengua e influir en la producción y comprensión de expresiones metafóricas. Así, incluso aunque compartan el 
mismo significado, las expresiones lingüísticas utilizadas pueden ser ligeramente diferentes como ser más sabio que un búho que en dariya se expresa con otro animal, la abubilla, por ser el búho un animal con connotaciones negativas en la cultura árabe. También podemos hallar expresiones totalmente diferentes, pero con un significado último similar, expresadas en ambos idiomas con elementos de la naturaleza: río revuelto, ganancia de pescadores; cuando el gato está ausente, los ratones se divierten; del árbol caído todos hacen leña; cuando cae el dromedario, todos sacan los cuchillos; a caballo regalado, no le mires el dentado; ¿qué es más dulce que la miel? El vinagre, si es de balde; después de la tempestad viene la calma; este mundo es un día miel y otro cebolla; ir a vendimiar y llevar uvas de postre; un comerciante lleva una carga de dátiles a Hayar.

Además, encontramos refranes que usan una expresión con elementos de la naturaleza en un idioma, pero no en el otro, aunque el significado final es el mismo: lo que no mata, engorda; de lo que crece en primavera, hay lo que harta o mata; tener la conciencia tranquila; hambre de perro en paz y no hartura con afán; el pez grande se come al chico; el fuerte se come al débil; mala hierba nunca muere; rómpele una costilla al niño, le saldrán dos; más vale prevenir que curar; si no estuviera esta nube, esta lluvia no habría venido.

En último lugar, existen refranes que no tienen traducción en el otro idioma como año de nieves, año de bienes o alto como una palmera, pero con cerebro de cabra. La naturaleza española se asocia al verdor, al agua, a la nieve, mientras que la lengua árabe implica calor, ovejas, arena o dromedarios (Ziyad Gogazeh 2005).

Junto a la naturaleza, la cultura material es otro de los elementos culturales que más dificultades puede provocar en la producción y la comprensión de metáforas, al ser muy particular de cada sociedad. Uno de los ejemplos más claros es la vestimenta. Pueden existir ropajes en una comunidad que no existan en la otra (sotanas, chilabas) y entonces, la equivalencia de significado no está disponible en la otra lengua por ausencia de terminología. De hecho, en español encontramos expresiones como gente de sotana logra lo que le da la gana y en árabe está como un beduino que se ha olvidado su capa, que resultan muy complicadas para extraer el significado metafórico si el interlocutor no comparte los conocimientos culturales de la otra lengua.

Otros campos temáticos incluidos dentro de la cultura social son los hábitos en el comer (al pan, pan y al vino, vino; no alimentes al beduino con 
kebab porque cada día llamará a tu puerta), las relaciones familiares ${ }^{(7)}$ (en árabe encontramos el tío materno se queda, el paterno se va(8); un primo tiene derecho a bajar a su prima de la yegua ${ }^{(9)}$; o el hijo de tu hijo es un hijo querido, pero el hijo de tu hija es hijo de extranjero ${ }^{(10)}$ ) o la situación social de la mujer (el vino y la mujer, el juicio hacen perder; el hombre que consulta a la mujer no es hombre sino mujer).

El tema de las herramientas o el dinero también pertenecen a la cultura material y puede influir en su forma de metaforizar. Efectivamente, encontramos ejemplos sobre este tema en ambos idiomas: en casa del herrero, cuchillo de palo; la puerta del carpintero está rota; el dinero atrae a los gorrones; tintinea tus monedas y te rodearán; ochavo a ochavo se junta un ducado; el dinar sobre el dinar hace dinero.

Además del clima y la naturaleza y de la cultura material y sus elementos, la cultura histórica en sus vertientes política y religiosa presenta muchos rasgos característicos que pueden hacer problemática la comprensión de las metáforas aparecidas en las paremias. Aunque ambas culturas parecen estar igual de influidas por la religión en muchas de sus expresiones metafóricas, las características de esas religiones difieren, lo que dificulta la intercomprensión. Encontramos expresiones como si el agua está presente para la ablución, el uso de la tierra se elimina o el marido de dos es un novio cada noche, que hacen

(7) Merece la pena señalar las ideas negativas sobre la familia que aparecen en los refranes árabes (aparecen con su homólogo en español en primer lugar): de tal palo, tal astilla; el defecto del niño, de su familia; ser la oveja negra, ser el hijo de la pata negra; educar a palos; al que no lo educa su familia, lo educan las noches y los días; aunque la mona se vista de seda, mona se queda; quien no lo aprecia por su pellejo, no lo aprecia por su hijo. Encontramos el proverbio árabe más vale infierno con pariente que paraíso con extraño, que en español tiene un significado más o menos equivalente, pero no limitado a las relaciones familiares: más vale malo conocido que bueno por conocer. Destacamos la existencia de refranes árabes marroquíes de los cuales nos ha resultado imposible encontrar un equivalente en español: casa llena no llena casa vacía («tener muchos hijos no garantiza que esos encuentren trabajo y ayuden a los padres»: traducción libre); tu padre, ¿qué te dejó?-Un cabrito que murió, parientes, serpientes; - Suegra ¿no fuiste nuera? - Lo fui y lo olvidé. De estos tres últimos no parece necesario explicar su significado.

(8) En árabe existen palabras diferentes para designar al tío materno y al paterno.

(9) En los países árabes es más común que en España las relaciones maritales entre primos.

(10) En la cultura árabe, los hijos solo reciben el apellido del padre y el de la madre desaparece, algo que no ocurre en la sociedad española.

AAM, 26 (2019) 19.1-20 
referencia a la preparación del rezo mediante la limpieza con agua del cuerpo (ablución) o la poligamia, característicos del islam. Ambas expresiones no tienen sentido en la lengua española. Por su parte, no es menos prolífica la lengua española para las expresiones religiosas: ir hecho un ecce homo; desvestir a un santo para vestir a otro; llorar como una Magdalena; ir más lento que una procesión; expresiones que también carecen de terminología en la religión musulmana. Sin embargo, muchas de estas expresiones religiosas en español sí que tienen su traducción en árabe, aunque no usando los mismos elementos: Dios lo cría y ellos se juntan; los pájaros de las mismas plumas se reúnen; a cada cerdo le llega su San Martín; a cada injusto le llega su fin; por ejemplo.

Para terminar, señalamos que la política y la historia también constituyen un campo temático abundante en expresiones paremiológicas. Así encontramos ejemplos como esperando un duque que no llegó la doncella envejeció; pensamos que un Pachá es un Pachá, pero es un hombre.

\section{Conclusiones}

A lo largo de este artículo se han presentado algunas de las semejanzas y diferencias más significativas que presentan las metáforas y su aparición en refranes en dos lenguas diferentes: el español peninsular y la dariya o árabe marroquí desde el punto de vista de la pragmática y de la escuela cognitiva.

La mayor parte de los estudios sobre la traducción de expresiones paremiológicas coincide en que la comprensión completa de los refranes y sus correspondientes expresiones metafóricas (especialmente las que derivan de metáforas estructurales, que son las más específicas de las lenguas y/o culturas) no se puede lograr sin el conocimiento sociocultural y la adquisición de la competencia sociolingüística de la lengua meta. El objetivo de este artículo ha sido exponer que esta circunstancia tampoco es posible sin el conocimiento sociolingüístico sobre este tipo de expresiones en la lengua materna del hablante que participa en una situación comunicativa intercultural. El aprendiente de una L2 debe disponer de las suficientes herramientas sociolinguísticas para poder comparar las semejanzas y diferencias entre las metáforas de ambas lenguas para poder llegar al significado último y completo de cualquier expresión metafórica y, de este modo, alcanzar el fin último de la adquisición de cualquier L2, convertirse en un hablante intercultural. 
Hemos puesto de manifiesto que la lengua árabe y la española peninsular presentan suficientes diferencias en su forma de metaforizar para que este fenómeno sociolingüístico sea tenido en cuenta y explicado de forma explícita desde los niveles iniciales de la adquisición de español por parte de aprendientes de origen árabe marroquí, porque es un aspecto que creemos que muchas veces es olvidado en el aula de idiomas.

\section{BIBLIOGRAFÍA}

ALBELDA, Marta. 2005. «El refuerzo de la imagen social en conversaciones coloquiales en español peninsular. La intensificación como categoría pragmática». Estudios de la descortesía en español, pp. 93-118.

ANAKI, David, FAUST, Miriam \& Shlomo KRAVETZ. 1998. «Cerebral hemispheric asymmetries in processing lexical metaphors». Neuropsychologia 36, 4, pp. 353-362.

ANDÚJAR GARCÍA, Itziar. 2016. Refranes y dichos populares en árabe, castellano e inglés: estudio contrastivo de los aspectos socioculturales. (Trabajo Fin de Grado). Barcelona, Universidad Autónoma de Barcelona.

BOUGHABA, Mohammed. 2014. «Las unidades fraseológicas y la traducción de culturemas entre el español y el árabe». Revista Paremia 23, pp. 209216.

BUSTOS, Eduardo de. 2000. «La metáfora: ensayos transdisciplinares». Fondo de Cultura Económica.

CASASANTO, Daniel. 2009. «Embodiment of abstract concepts: good and bad in right-and left-handers». Journal of Experimental Psychology General, 138, 3, pp. 351-367.

CHAMIZO DOMÍNGUEZ, Pedro. 2005. La metáfora (semántica y pragmática). Teoría crítica-e.

CURCÓ, Carmen. 1998. «No me harías un favorcito?: reflexiones en torno la expresión de la cortesía verbal». La pragmática lingüística del español: Recientes desarrollos 22, pp. 129-171. 
CURCÓ, Carmen. 2014. «Un comentario en torno a la noción de imagen». En: La (des) cortesía en el discurso: Perspectivas interdisciplinarias (imagen, actos de habla y atenuación), pp. 19-52.

DANESI, Marcel. 2004. Metáfora, pensamiento y lenguaje. Sevilla, Kronos.

DANESI, Marcel. 2014. Diccionario de medios y comunicaciones. Routledge.

DUFFÉ MONTALVÁN, Aura Luz. 2004. «Reflexiones psicolingüísticas y didácticas sobre el estudio de metáforas y modismos». Didáctica (Lengua y Literatura) 16, pp. 33-44.

EL MADKOURI, Mohammed. 2010. «La traducibilidad del refranero entre el árabe y el español». Tonos Digital: revista electrónica de estudios filológicos, 20.

ELDIN SHALAN, Mona Salah. 2012. «Diseño de una base de datos informática para la elaboración de un diccionario fraseológico español-árabe». En: González Rey, María Isabel (ed.). Unidades fraseológicas y TIC. Madrid, Instituto Cervantes, pp. 83-96.

FERNÁNDEZ COLOMER, María José. 2003. «La metáfora en el español coloquial» Interlingüística 14, pp. 359-374.

FERNÁNDEZ COLOMER, María José \& ALBELDA, Marta. 2001. «Metáfora e intensificación». En: Actas del XXIII Congreso Internacional de Lingüística y Filología Románica. Tübingen, Max Niemeyer, vol. 2.

GIBBS Jr, Raymond W. 2006. «Cognitive and metaphor research: past successes, skeptical questions, future challenges». DELTA: Documentação de Estudo em Lingüística Teórica e Aplicada, 22 (SPE), pp.1-20.

GIBBS Jr, Raymond W. \& MACEDO, ACPSD. 2010. «Metaphor and embodied cognition». DELTA: Documentação de Estudo em Lingüística Teórica e Aplicada, 26 (SPE), pp.679-700.

GIBBS, Raymond. 1994. The poetics of mind: Figurative thought, language, and understanding. Cambridge, Cambridge University Press.

GONZÁLEZ PÉREZ, Rosario. 2008. «Reanálisis semántico, procesos metafóricos y polisemia». En: Olza Moreno, Inés \& Manuel, Casado Velarde (eds.). Actas del XXXVII Simposio Internacional de la Sociedad Española de Lingüística. Pamplona, Servicio de Publicaciones de la Universidad de Navarra.

GRADY, Joseph. 1997. Foundations of meaning: Primary Metaphors and Primary Scenes. California, Universidad de Berkley (tesis doctoral). 
GRICE, H. Paul. 1989. Estudios en el camino de las palabras. Harvard University Press.

IBARRETXE-ANTUÑANO, Iraide. 1999. Polysemy and metaphor in perception verbs: a cross-linguistic study. Edimburgo, Universidad de Edimburgo (tesis doctoral).

JAKEL, Olaf. 1997. Metafora w abstrakcyjnych domenach dyskursu: kognitywno-lingwistyczna analiza metaforycznych modeli aktywności umystowej, gospodarki i nauki. Cracovia, Universidad de Cracovia (tesis doctoral).

KOVECSES, Zoltán. 2000. «The scope of metaphor». Metaphor and metonymy at the crossroads: A cognitive perspective, pp. 79-92.

LAKOFF, George. 1990. «The invariance hypothesis: Is abstract reason based on image-schemas?». Cognitive Linguistics (includes Cognitive Linguistic Bibliography) 1, 1, pp. 39-74.

LAKOFF, George \& Mark JOHNSON. 1980. «Metáfora conceptual en el lenguaje cotidiano». Revista de Filosofía 77, 8, pp. 453-456.

LAKOFF, George \& Mark JOHNSON. 1986. Metáforas de la vida cotidiana. Teorema, SIDALC.

LAKOFF, George \& Mark JOHNSON. 1998. Leben in Metaphern. Konstruktion und Gebrauch von Sprachbildern. Heidelberg, 72011.

LAKOFF, George \& Mark JOHNSON. 2003. Metáforas por las que vivimos. Chicago, Universidad de Chicago Press.

LAKOFF, George \& Mark TURNER, M. 1989. More than cool reason: a field guide to poetic metaphor. Chicago, Universidad de Chicago Press.

LAKOFF, George \& Zoltán KOVECSES. 1987. «El modelo cognitivo de la ira inherente al inglés americano». Modelos culturales en lenguaje $y$ pensamiento, pp. 195-221.

MARTÍNEZ KLEISER, Luis. 1978. Refranero general ideológico español. Hernando.

MERINO JULAR, Elena. 2010. «Culturas y creencias malentendidas dentro y fuera de la clase de L2 para inmigrantes adultos». Bellaterra Journal of Teaching \& Learning Language \& Literature 3, 1, pp. 70-87.

MILLÁN, José Antonio \& NAROTSKY, Susana. 2009. Introducción a Metáforas de la vida cotidiana. Madrid, Cátedra. 
MOSCOSO, Francisco. 2010. «Idiomatismos en árabe marroquí». En: MOGORRÓN HUERTA, Pedro \& MEJRI, Salah (dirs.). Opacidad, idiomaticidad y traducción. Alicante, Universidad de Alicante.

NUNBERG, G. SAG, I. A. \& WASOW, T. 1994. «Modismos». Idioma 70, pp. 491-538. Database Name: CSA Linguistics and Language Behavior Abstract.

OULD MOHAMMED BABA, Ahmed Salem. 1996. «Refranes en dialecto árabe hassaniya». Anaquel de Estudios árabes 7, pp. 145-240.

PAMIÉS BERTRÁN, Antonio. 2002. «Modelos icónicos y archimetáforas: algunos problemas metalingüísticos en el ámbito de la fraseología». Language design: journal of theoretical and experimental linguistics 4, pp. 9-20.

PARENTE, Diego. 2000. «Literalidad, metáfora y cognición. Observaciones críticas sobre la perspectiva experiencialista de Lakoff y Johnson». A Parle rei: revista de filosofía 11.

POLLIO, Howard. 1977. Psychology and the poetics of growth: Figurative language in psychology, psychotherapy, and education. Lawrence Erlbaum Associates.

RUIZ DE MENDOZA, Francisco José. 1996. «Understanding through metonymy: the role of metonymy in communication and cognition». En: The Pragmatics of Understanding and Misundersranding. Zaragoza, Universidad de Zaragoza.

RUIZ DE MENDOZA, Francisco José. 2000. «The role of mappings and domains in understanding metonymy». En: Metaphor and metonymy at the crossroads. A cognitive perspective, pp. 109-132.

RUIZ DE MENDOZA, Francisco José \& Nuria DEL CAMPO. 2012. «A constructionist approach to illocution: The case of orders». Miscelánea: A Journal of English and American Studies 45.

RUIZ MORENO, Rosa María. 2000. «El refrán árabe y su forma de expresión». Revista Paremia 9, pp. 125-132.

SANTIAGO, Julio, LUPIAÑEZ, Juan, PÉREZ, Emilio \& FUNES, María José. 2007. «Time (also) flies from left to right». Psychonomic Bulletin Review 14,3 , pp. 512-516.

SEVILLA MUÑOZ, Julia \& Carlos CRIDA ALVÁREZ. 2013. «Las paremias y su clasificación». Revista Paremia 22, pp. 105-114. 
SHARIFIAN, Farzardy Gary, PALMER. 2007. Lingüística cultural aplicada: implicaciones para el aprendizaje de una L2 y la comunicación intercultural. John Benjamins Publishing.

SORIANO, Cristina. 2012. «La metáfora conceptual». En Ibarretxe-Antuñano, Iraide \& Javier, Valenzuela (eds.). Lingüística cognitiva. Barcelona, Antrophos.

SPERBER, Dan \& Deirdre WILSON. 1986. Relevancia: comunicación y cognición 182, Cambridge, Harvard University Press.

VELA, J. 2014. La metáfora como mecanismo de valoración: aproximación al estudio de las estrategias lingüísticas de expresión de la actitud en la interacción oral. Alicante, Universidad de Alicante (tesis doctoral).

ZIYAD Gogazeh. 2005. «Problemas culturales y lingüísticos en la traducción de refranes del árabe al español y viceversa». Revista Paremia 14, pp. 61-70. 